\title{
Evaluating the Impacts of Different Interventions on Quality in Concept Gen- eration
}

\section{Mr. Kevin Charles Helm, The Pennsylvania State University}

Kevin Helm is a graduate student at The Pennsylvania State University. Since Fall 2014, he has studied cognitive research in engineering design with support from Dr. Kathryn Jablokow. He received a B.S. in Mechanical Engineering in 2015 from the Schreyer Honors College at Penn State.

\section{Dr. Kathryn W. Jablokow, Pennsylvania State University}

Dr. Kathryn Jablokow is an Associate Professor of Mechanical Engineering and Engineering Design at Penn State University. A graduate of Ohio State University (Ph.D., Electrical Engineering), Dr. Jablokow's teaching and research interests include problem solving, invention, and creativity in science and engineering, as well as robotics and computational dynamics. In addition to her membership in ASEE, she is a Senior Member of IEEE and a Fellow of ASME. Dr. Jablokow is the architect of a unique 4-course module focused on creativity and problem solving leadership and is currently developing a new methodology for cognition-based design. She is one of three instructors for Penn State's Massive Open Online Course (MOOC) on Creativity, Innovation, and Change, and she is the founding director of the Problem Solving Research Group, whose 50+ collaborating members include faculty and students from several universities, as well as industrial representatives, military leaders, and corporate consultants.

\section{Dr. Shanna R. Daly, University of Michigan}

Shanna Daly is an Assistant Professor of Mechanical Engineering at the University of Michigan. She has a B.E. in Chemical Engineering from the University of Dayton (2003) and a Ph.D. in Engineering Education from Purdue University (2008). Her research focuses on strategies for design innovations through divergent and convergent thinking as well as through deep needs and community assessments using design ethnography, and translating those strategies to design tools and education. She teaches design and entrepreneurship courses at the undergraduate and graduate levels, focusing on front-end design processes.

\section{Dr. Eli M. Silk, Rutgers, The State University of New Jersey}

Eli Silk is an Assistant Professor of Professional Practice in the Graduate School of Education at Rutgers, The State University of New Jersey.

\section{Dr. Seda Yilmaz, Iowa State University}

Dr. Yilmaz is an Associate Professor of Industrial Design. She teaches design studios and lecture courses on developing creativity and research skills. Her current research focuses on identifying impacts of different factors on ideation of designers and engineers, developing instructional materials for design ideation, and foundations of innovation. She often conducts workshops on design thinking to a diverse range of groups including student and professional engineers and faculty member from different universities. She received her PhD degree in Design Science in 2010 from University of Michigan. She is also a faculty in Human Computer Interaction Graduate Program and the ISU Site Director for Center for e-Design.

\section{Mr. Rafael Suero, The Pennsylvania State University}

Rafael Suero is an undergraduate student at the Pennsylvania State University. He is pursuing a double major in Mechanical and Nuclear Engineering. He joined the Ideation Flexibility Lab in Fall of 2014. He then participated in a Research Experience for Undergraduates program conducted by the College of Engineering Research Initiative at PSU, which only helped to heighten his interest in engineering design and education research. In Fall of 2015, Rafael also joined Jessica Menold in her doctoral research involving prototyping. 


\title{
Evaluating the Impacts of Different Interventions on Quality in Concept Generation
}

\begin{abstract}
Producing ideas of high quality has great importance in engineering design. Although concept generation is sometimes one of the shorter phases of a project, concept generation that leads to viable and unique solutions can greatly contribute to a product's final outcomes. Concept generation also has importance as a tool for engineering education and academic research. Because the quality of solutions can vary from individual to individual and from circumstance to circumstance, it would be useful to better understand how different interventions influence the outcomes of the ideation process in the concept generation stage of engineering design. In this work, we investigated the impacts of the problem context and three specific interventions designed to increase the ideation flexibility for the outcomes of concept generation. The three interventions were problem framing, design tools, and teaming. Our results show that both problem framing and teaming impact several aspects of quality, while design tools only impact the quantity of ideas produced.
\end{abstract}

\subsection{Introduction}

This paper investigates interventions and their impact on concept generation; its main concern is which interventions affect the quality of an individual's ideas and in what ways. The interventions under consideration include teaming, design tools, and problem framing, as well as problem context. Problem context refers to the focus of concept generation - i.e., the given design task. In this work, four unique problem contexts were studied. The three interventions teaming, design tools, and problem framing - were created to aid the ideation process. Teaming encourages participants to share ideas as they work in teams, and design tools provide helpful design heuristics. Problem framing alters a given problem context with respect to expectations and constraints. In combination, these interventions are intended to promote ideation flexibility, one's ability to switch between preferred and non-preferred methods of concept generation as preferred by the problem. Given insight into how the three interventions impact idea quality, engineers, educators, and students will be able to make informed decisions about which interventions to use under different conditions with different concept generation goals in mind.

\subsection{Concept Generation}

Concept generation or ideation is the primary means by which solutions are created. These solutions to engineering problems, frequently referred to as ideas or concepts, undergo a vetting process to select which solutions warrant further development. The outcomes of concept generation and selection can have far-reaching implications in industry, so ideation researchers have investigated and proposed many methods to promote better ideas and to evaluate quality ${ }^{1}$. In the research presented here, undergraduate engineering students participated in sessions of concept generation for various design problems. These participants recorded their responses on idea sheets (one concept per sheet). Each idea sheet included space for drawing sketches and writing explanations as shown in Figure $1^{2}$. 


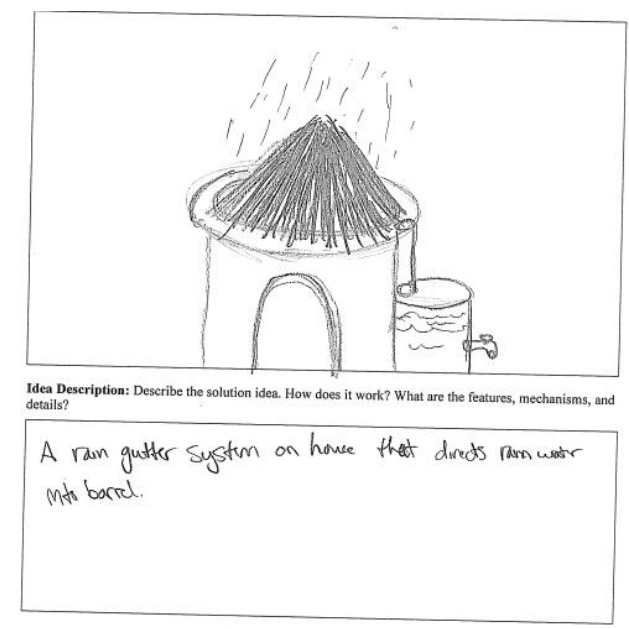

Figure 1: Example Idea Sheet from Rainwater Catcher Context

Researchers and designers have offered many competing strategies for improving the effectiveness of ideation sessions. Brainstorming, a group ideation method intended to produce many ideas, is frequently used and studied ${ }^{3}$; however, instructions designed to improve brainstorming and increase idea quantity have proven unreliable ${ }^{4}$. Alternatives to brainstorming such as TRIZ or "brainwriting" promote different outcomes. TRIZ asks designers to consider the principle issues of a problem and then adapt previous concepts that addressed similar issues ${ }^{5}$, whereas "brainwriting" encourages team members to record their own solutions separately to prevent group criticism or pressure during brainstorming sessions ${ }^{6}$. Each of these techniques has both benefits and drawbacks depending on the problem, the participants, and the overall problem solving process involved. Because these strategies have varying and subjective impacts on concept generation, a formal and more objective approach is needed. Measuring the quality of ideas using metrics is one means of evaluation.

\subsection{Measuring Quality}

To understand the strategies and interventions used to promote ideation, reliable tools are required to evaluate the ideas that result. As with concept generation, many researchers have proposed methods for idea evaluation. One early study used quantity as a measure of quality ${ }^{3}$; however, research claims regarding that association have been questioned ${ }^{7}$. After performing a comprehensive literature review of existing ideation research, Dean, et al. created a quality framework that summarizes many dimensions of quality, as shown in Table 1. Dean, et al. then subdivided these dimensions to create seven independent quality metrics as shown in Table 2 (and Appendix A).

As shown in Appendix A, each quality metric is designed to evaluate that sub-dimension on an ordinal scale ( 1 to $\mathrm{X}$ ) without regard to the other metrics (i.e., they are independent). For instance, the clarity metric shown in Table 3 provides a scored measurement $(1,2$, or 3 ) of an idea's level of clarity in terms of communication. Using this metric, a team of researchers or "coders" evaluates an idea's clarity using well established "coding" procedures ${ }^{14}$. These 
procedures provide clear directions for applying these metrics, and more importantly, they ensure sufficient inter-rater reliability.

Table 1: Dimensions of Quality

\begin{tabular}{|c|l|}
\hline Relevance & $\begin{array}{l}\text { The idea applies to the stated problem and will be effective at solving the } \\
\text { problem }\end{array}$ \\
\hline Specificity & An idea is specific if it is clear (worked out in detail) \\
\hline Workability & $\begin{array}{l}\text { An idea is workable (feasible) if it can be easily implemented and does } \\
\text { not violate known constraints }\end{array}$ \\
\hline
\end{tabular}

Table 2: Definitions of Quality Metrics

\begin{tabular}{|c|c|c|c|}
\hline Category & Metric & Description & Rating Scale \\
\hline \multirow[t]{2}{*}{ Relevance } & Applicability & $\begin{array}{l}\text { The degree to which the idea } \\
\text { clearly applies to the stated } \\
\text { problem }\end{array}$ & 1 to 4 \\
\hline & Effectiveness & $\begin{array}{l}\text { The degree to which the idea } \\
\text { will solve the problem }\end{array}$ & 1 to 4 \\
\hline \multirow[t]{3}{*}{ Specificity } & $\begin{array}{l}\text { Implicational } \\
\text { Explicitness }\end{array}$ & $\begin{array}{l}\text { The degree to which there is a } \\
\text { clear relationship between the } \\
\text { recommended action and the } \\
\text { expected outcome }\end{array}$ & 1 to 3 \\
\hline & Completeness & $\begin{array}{l}\text { The number of independent } \\
\text { subcomponents into which the } \\
\text { idea can be decomposed, and the } \\
\text { breadth of coverage with regard } \\
\text { to who, what, where, when, why, } \\
\text { and how }\end{array}$ & 1 to 3 \\
\hline & Clarity & $\begin{array}{l}\text { The degree to which the idea is } \\
\text { clearly communicated with } \\
\text { regard to grammar and word } \\
\text { usage }\end{array}$ & 1 to 3 \\
\hline \multirow[t]{2}{*}{ Workability } & Acceptability & $\begin{array}{l}\text { The degree to which the idea is } \\
\text { socially, legally, or politically } \\
\text { acceptable }\end{array}$ & 1 to 4 \\
\hline & Implementability & $\begin{array}{l}\text { The degree to which the idea can } \\
\text { be easily implemented }\end{array}$ & 1 to 4 \\
\hline
\end{tabular}


Table 3: Clarity Metric

\begin{tabular}{|c|l|}
\hline Score & \multicolumn{1}{|c|}{ Level Description } \\
\hline 3 & $\begin{array}{l}\text { Well-developed written description or visual representation. The components } \\
\text { are clear and commonly understood }\end{array}$ \\
\hline 2 & $\begin{array}{l}\text { Understandable but some of the descriptions or drawings might not be } \\
\text { commonly understood. Contains fragments or obviously missing components } \\
\text { to make the concept clear }\end{array}$ \\
\hline 1 & Written description and drawing are vague/ambiguous. Difficult to understand. \\
\hline
\end{tabular}

\subsection{Ideation Interventions and Quality}

This research investigated whether problem context and the following three interventions influenced the quality of design concepts: teaming, design tools, and problem framing. To examine these interventions, the same experimental procedure was used in all studies.

Participants engaged in two sessions of concept generation. The first session acted as a control case, and the second session introduced an intervention. Four different problem contexts were used, as shown in Table 4. All four problem contexts came from previous studies in engineering design, but each was modified to create similarity in writing style. A previous study of these contexts showed that their difficulty was comparable ${ }^{10}$. To further investigate that these contexts are similar, studies using all four contexts were conducted to determine if changing context corresponds to any changes in quality.

\section{Table 4: List of Problem Contexts}

\begin{tabular}{|l|l|}
\hline Snow Transporter & $\begin{array}{l}\text { Design a means of snow transportation alternative to skiing or } \\
\text { snowboarding that requires less skill }\end{array}$ \\
\hline Jar Opener & $\begin{array}{l}\text { Design a means for the elderly or disabled with limited use of an } \\
\text { upper extremity to open jars or lidded-containers }\end{array}$ \\
\hline Belonging Securer & $\begin{array}{l}\text { Design a means for conveniently securing unattended personal items } \\
\text { in public areas }{ }^{10}\end{array}$ \\
\hline Rainwater Catcher & Design a means of water collection and storage for rural villages ${ }^{10}$ \\
\hline
\end{tabular}

For the teaming intervention, participants were randomly assigned to work in pairs. Previous research has shown that teaming has complex effects. For instance, ideation in two-person teams has been shown to affect outcome perceptions with regard to diversity and elaboration; these perceptions may be different from the actual outcomes of the ideation ${ }^{2}$.

Another intervention used the 77 Cards created by Daly, Yilmaz, and Seifert ${ }^{11}$ as design tools. For the design tools intervention, students were given a set of cards from the handbook. Each card provides a heuristic that can be used to generate new design ideas, as well as examples of the design heuristic in use, as shown in Figure 2. In previous research, these cards have been used to study the quantity and variety of ideas produced ${ }^{11}$. 

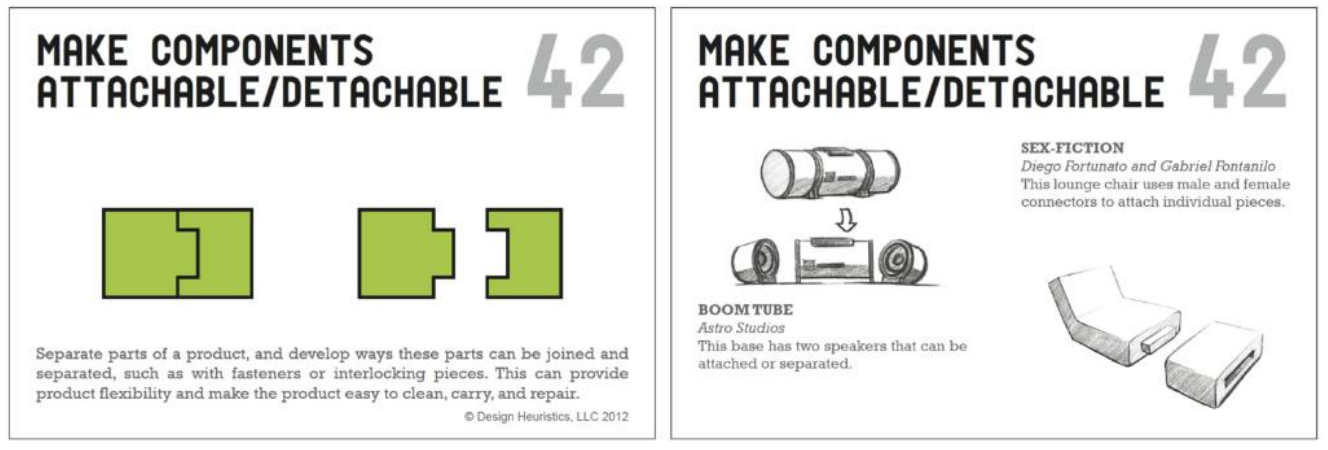

Figure 2: Example from the 77 Cards (Back and Front Sides) $)^{11}$

Problem Framing was the last intervention used in this research. Using the Design Problem Framework $^{12}$, three sets of instruction were created for each problem context. For instance, for the snow transporter problem context, participants were instructed to use one of the three preprepared prompts shown in Figure $3^{12}$. The first prompt uses neutral framing; neutral framing refers to the basic criteria of a problem context and has been shown to encourage participants to generate ideas using their preferred, natural approach. The other two prompts utilize problem framing, as written in bold text. The second prompt focuses on modification and progressive design using adaptive framing, whereas the third prompt focuses on novelty and alternative approaches using innovative framing. These prompts are framed to emulate Kirton's AdaptionInnovation Theory, which models the continuum of cognitive style ${ }^{13}$. Problem framing as an intervention has been studied previously with regard to an individual's cognitive style and perceptions. A goal of the current research was to study problem framing using the actual outcomes instead of individual perceptions.

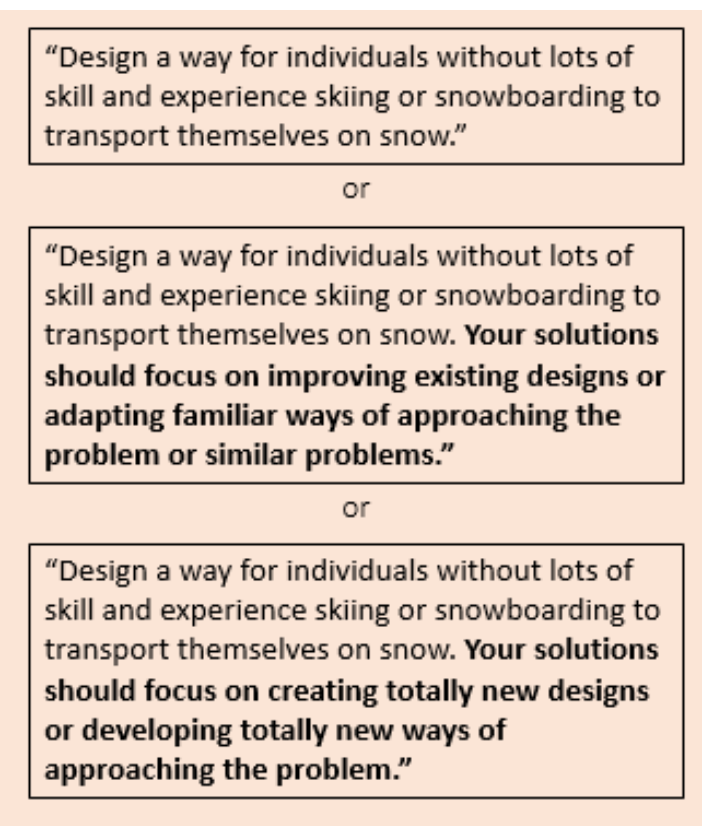

Figure 3: Problem Framing in the Snow Transporter Context ${ }^{12}$ 


\subsection{Research Method}

In this research, problem context and the three interventions were examined separately in four individual studies, as shown in Figure 4. The primary research question was how each of the problem contexts and interventions impacted quality.

\begin{tabular}{|l|}
\hline Study 1: Problem Context \\
\hline Study 2: Teaming \\
\hline Study 3: Design Heuristics \\
\hline Study 4: Problem Framing \\
\hline
\end{tabular}

Figure 4: List of Research Studies

\subsection{Participants and Data Collection}

Each study involved engineering students from Iowa State University, The Pennsylvania State University, and The University of Michigan. These students were primarily freshmen and sophomores taking lower-level engineering design courses. Each sample of participants completed two ideation sessions. During each ideation session, participants were instructed to generate ideas and then record their responses using words and sketches. Participants were not instructed to grade their work or produce a certain number of ideas. The ideas generated in these studies were then evaluated using the "coding" process described earlier. In Tables 5, 6, 7, 8, and 9 , the number of participants and their quantity of ideas is recorded for each study.

Table 5: Participants and Ideas in Problem Context Study

\begin{tabular}{|c|c|c|}
\hline Belonging Securer & 42 participants & 151 ideas \\
\hline Jar Opener & 40 participants & 141 ideas \\
\hline Rainwater Catcher & 34 participants & 106 ideas \\
\hline Snow Transporter & 43 participants & 153 ideas \\
\hline Total & 159 participants & 551 ideas \\
\hline
\end{tabular}

Table 6: Participants and Ideas in Teaming Study

\begin{tabular}{|c|c|c|}
\hline Neutral Session & \multirow{4}{*}{86 participants } & 303 ideas \\
Teaming Session & 259 ideas \\
Total & 562 ideas \\
\hline
\end{tabular}

Table 7: Participants and Ideas in Design Tools Study

\begin{tabular}{|c|c|c|}
\hline Neutral Session & \multirow{4}{*}{26 participants } & 107 ideas \\
Design Tools Session & 75 ideas \\
\hline Total & & 182 ideas \\
\hline
\end{tabular}


Table 8: Participants and Ideas in Adaptive Problem Framing Study

\begin{tabular}{|c|c|c|}
\hline Neutral Session & \multirow{3}{*}{25 participants } & 77 ideas \\
Adaptive Session & & 72 ideas \\
\hline Total & & 149 ideas \\
\hline
\end{tabular}

Table 9: Participants and Ideas in Innovative Problem Framing Study

\begin{tabular}{|c|c|c|}
\hline Neutral Session & \multirow{3}{*}{21 participants } & 61 ideas \\
Innovative Session & 55 ideas \\
\hline Total & & 116 ideas \\
\hline
\end{tabular}

\subsection{Data Analysis}

After collecting ideas for each study, teams of researchers used the "coding" process and quality metrics to determine quality scores for each idea. These ideas were then sorted by participant and averaged to calculate each participant's overall quality scores. Each participant had quantity of ideas produced and average scores for each of the quality metrics. For the problem context study, participants from the four contexts were analyzed to investigate how they performed with relation to context. Because no participants attempted more than one neutral problem context, non-paired Welch's t-tests were used for this analysis. These t-tests compared each of the subscores of quality from one context to another. In addition to quality, the quantity of ideas generated by each participant was also examined.

For the studies involving interventions, the quality of each individual's ideas was compared across sessions. For the teaming intervention, each participants' set of ideas was examined to show how they performed with and without a team. In design tools, each participants' set of ideas was examined for how well they performed with and without the tools. In problem framing, they were examined for how well they performed with and without problem framing. The difference in quality scores for each individual was used to investigate how interventions affect aspects of quality. Unlike the problem context study, the intervention studies used paired Welch's t-tests with respect to each quality score. In addition to quality, the quantity of ideas was also examined.

For all studies, participants attempted a different problem context in the second ideation session. Changing problem context could have been a confounding factor in the intervention studies; however, the alternative, such as attempting the same problem context twice, was deemed a worse case. To handle the issue of changing context, two contexts similar in complexity were used for each intervention study.

A key concern in this research was producing statistically significant results. Each t-test had to have a p-value less than 0.05 and a power value greater than 0.80 to be considered significant. Because of these requirements, many of the t-tests yielded non-significant results. 


\subsection{Problem Context Results}

Results for comparing by problem context show that several aspects of quality have statistically significant differences. The results, as reported in Table 10, show the differences in quality for each comparison that have a p-value less than 0.05 . In Table 10, each cell represents the differences on average between one problem context and another. This study had four separate groups of participants generate ideas (one group for each problem context), so there are six total combinations or table cells for comparing problem context. The differences in each cell are equivalent to row minus column. For instance, the cell associated with differences between the jar opener and snow transporter problem contexts indicates that participants responding to the jar opener problem context had higher applicability and implementability scores.

Table 10: Summarization of Differences by Comparing Problem Context

\begin{tabular}{|c|c|c|c|c|}
\hline & Snow & Jar & Belonging & Rain \\
\hline \multicolumn{5}{|l|}{ Snow } \\
\hline Jar & $\begin{array}{l}\text { Applic. } 0.29 \\
\text { Implement. } 0.19\end{array}$ & & & \\
\hline Belonging & $\begin{array}{l}\text { Accept. } 0.20 \\
\text { Clarity } 0.15 \\
\text { Imp. Exp. }-0.34\end{array}$ & $\begin{array}{l}\text { Applic. -..38 } \\
\text { Implic. Exp. }-0.25\end{array}$ & & \\
\hline Rain & $\begin{array}{l}\text { Applic. } 0.26 \\
\text { Implement. } 0.20 \\
\text { Accept. } 0.20 \\
\text { Clarity } 0.25\end{array}$ & $\begin{array}{l}\text { Effect. } 0.26 \\
\text { Clarity } 0.21\end{array}$ & $\begin{array}{l}\text { Effect. } 0.32 \\
\text { Applic. } 0.35 \\
\text { Imp. Exp. } 0.30\end{array}$ & \\
\hline \multicolumn{5}{|c|}{ Abbreviations: } \\
\hline \multicolumn{5}{|c|}{$\begin{array}{l}\text { Snow - Snow Transporter } \\
\text { Jar - Jar Opener } \\
\text { Belonging - Belonging Securer } \\
\text { Rain - Rainwater Catcher }\end{array}$} \\
\hline $\begin{array}{l}\text { Appli } \\
\text { Effec } \\
\text { Imp. I } \\
\text { Accel } \\
\text { Imple }\end{array}$ & $\begin{array}{l}\text { Applicability } \\
\text { Effectiveness } \\
\text { - Implicational Expl } \\
\text { Acceptability } \\
\text { t. - Implementability }\end{array}$ & tness & & \\
\hline
\end{tabular}


Looking at all of these changes, the snow transporter and rainwater catcher contexts appear to have the most differences with one another (4 total). On average, participants produce ideas with higher applicability, implementability, acceptability, and clarity when responding to the rainwater catcher context instead of the snow transporter context. One possible explanation for these changes is that participants are more familiar and prepared with the rainwater context. The results also suggest that the belonging securer context has several differences with the snow transporter and rainwater catcher contexts. The majority of differences on average across all contexts appear to be related to applicability, clarity, and implicational explicitness, and fewer differences on average are observed with regard to effectiveness, implementability, and acceptability. No differences on average are with regard to quantity of ideas.

A more practical question is whether these average differences are even noticeable. Considering only the statistically significant sub-scores, most of these differences are approximately 0.25 (with a maximum difference of 0.38 and a minimum difference of 0.15 ). Many of these metrics are scored as either $1,2,3$, or 4 . For a metric that scores from one to four, a difference of 0.20 is only about five percent of the total scale. Because these differences are small compared to the scales by which these metrics are measured, context may have a negligible impact with regard to quality in comparison to other factors, such as the three interventions.

\subsection{Teaming Results}

Results for the teaming intervention show that several aspects of quality have statistically significant in magnitude. The four significant t-tests are shown in Table 11. The results of these tests indicate that only effectiveness appears to increase (on average) in response to the teaming intervention, whereas quantity, clarity, and implicational explicitness are shown to decrease.

This positive outcome in effectiveness may be due to the shared knowledge of teammates, but it is also associated with a net loss in ideas. Teaming appears to yield fewer ideas on average, and many of these ideas generally have lower scores with regard to metrics focused on communication (clarity).

Table 11: Average Paired Differences due to Teaming

\begin{tabular}{|c|c|c|c|}
\hline Metric & Mean Difference & \% Difference & P-Value \\
\hline Quantity & -0.51 & N/A & 0.001 \\
\hline Effectiveness & 0.15 & $3.7 \%$ & 0.033 \\
\hline Clarity & -0.12 & $4.0 \%$ & 0.044 \\
\hline $\begin{array}{c}\text { Implicational } \\
\text { Explicitness }\end{array}$ & -0.21 & $7.1 \%$ & 0.003 \\
\hline
\end{tabular}

These changes in quality due to teaming may occur because team members are more focused on deliberating than writing many well-thought responses. It is possible that these groups dedicated more time to the criteria used to measure effectiveness. They may have been less motivated or had less remaining time to produce more ideas and write detailed explanations on the idea sheets.

The remaining concern is if any of these differences are readily apparent. As with the previous study regarding problem context, the percent changes for effectiveness and clarity are less than 
five percent. Implicational explicitness increased roughly seven percent on average. More research is needed to determine the accuracy and implications of these changes. Based on a lack of strong outcomes, basic teaming does not guarantee an improvement.

\subsection{Design Tools}

In comparison to teaming and problem context, the study on design tools yielded fewer statistically significant results. Only the quantity of ideas is shown to change with a p-value less than 0.001 and a magnitude of 1.23 ideas. On average, participants produced 1.23 ideas fewer while using design tools. Compared to any of the teaming and problem context results, the magnitude of this change is more significant. One possible reason for fewer ideas is that participants devoted more of their time to reading the cards, understanding them, and then selecting which cards to use. This spent time fixating on the tools could explain why participants using the tools produced fewer ideas on average.

\subsection{Problem Framing}

The statistically significant t-tests, as shown in Table 12 and Table 13, suggest that problem framing is associated with few average changes in quality and quantity. The adaptive framing group showed a general increase in both effectiveness and acceptability. These results are expected, because the adaptive framework instructs participants to produce ideas that improve existing design or use familiar approaches to the problem. In the literature, high acceptability is often associated with the adaptive framework. The loss in quantity of ideas is not unexpected, since participants are supposed to feel constrained to a more limited type of idea generation.

Table 12: Results of Adaptive Framing Intervention

\begin{tabular}{|l|l|l|l|}
\hline \multicolumn{4}{|c|}{ Paired t-tests for Adaptive Framing Intervention } \\
\hline Metric & Mean Difference & $\%$ Difference & P-Value \\
\hline Quantity & -0.81 & N/A & 0.012 \\
\hline Effectiveness & 0.38 & $9.4 \%$ & 0.038 \\
\hline Acceptability & 0.21 & $5.3 \%$ & 0.048 \\
\hline
\end{tabular}

Table 13: Results of Innovative Framing Intervention

\begin{tabular}{|l|l|l|l|}
\hline \multicolumn{4}{|c|}{ Paired t-tests for Innovative Framing Intervention } \\
\hline Metric & Mean Difference & $\%$ Difference & P-Value \\
\hline Clarity & 0.19 & $6.2 \%$ & 0.039 \\
\hline
\end{tabular}

Unlike the adaptive framing group, the innovative framing group showed only a change in clarity. This increase suggests that, on average, participants working under the innovative framework produced more easily understandable ideas that had more detail. An increase in clarity is not necessarily expected in this case based on the literature. More investigation is needed to explain why clarity could be associated with innovative framing. 


\subsection{Discussion and Conclusions}

Studies reported here provide some evidence that certain aspects of quality may be affected to some extent by the three interventions. Many of these results support what is expected from past research. With problem context, differences in quality may be expected intuitively, especially when the complexity and familiarity of contexts varies. The snow transporter context, one of the more detailed contexts, is shown to have the most differences in quality with the other problem contexts, yet the magnitudes of these differences are marginal. Like problem context, problem framing and teaming also appear to influence quality marginally. These small changes fail to suggest that either basic teaming or problem framing have major impacts on their own.

At a broader level, the results of the interventions touch all three categories of quality. In teaming, the effectiveness metric (a sub-dimension of relevance) improved, but the quantity and specificity of ideas declined. Problem framing instead impacted workability (adaptive framing) and specificity (innovative framing). If these interventions were to be applied and act independently, then all three categories of quality would be impacted. As might be expected, each intervention has a complex relationship with quality, and more work is needed to determine the significance and impact of these changes. A clearer understanding of these interventions and their trade-offs may allow educators and engineers to better use these interventions and broaden their ideation flexibility.

\subsection{Limitations and Caveats}

Several aspects of this research limit our conclusions. One issue with the teaming intervention is that randomized pairings were used. It is possible that the randomized pairs used in these studies do not reflect ideal groupings. Another issue with this work is that participants undergo two sessions of ideation. After the first session, participants may be mentally fatigued. Most importantly, participants receiving an intervention also change problem context. The case studies involving just problem context suggest this change is negligible; however, it is possible that participants are more capable in one context. An ideal study would have participants use the same context to evaluate teaming or design tools, yet an issue would be that the participants would have already experienced that same problem context.

\subsection{Future Work}

To provide more insight to the relationships between these interventions and quality, further investigations are necessary. For instance, more elaborate studies for teaming and problem framing are also needed. By creating and managing pairs instead of using randomization, more interesting group dynamics might be observed, and with problem framing, individuals could be studied with regard to their predisposition toward innovative or adaptive framing. This additional information should help educators maximize the potential of teaming in the classroom and teach students how to be more flexible thinkers. 


\subsection{Acknowledgements}

This research was supported by the National Science Foundation through Research in Engineering Education (REE) Grants \#1264715, \#1265018, \#1264551.

\subsection{References}

[1] Ulrich, Karl T., and Steven D. Eppinger. Product Design and Development. NewYork: McGraw-Hill, 1995.

[2] Jablokow, K. W., Teerlink, W., Yilmaz, S., Daly, S. R., \& Silk, E. M. (2015, June).The impact of teaming and cognitive style on student perceptions of design ideation outcomes.

[3] Briggs, R.O., Bruce A. Reinig, M.M. Shepherd, J. Yen, and J.F. Nunameker. 1997. "Quality as a Function of Quantity in Electronic Brainstorming." In Proceedings of the Thirtieth Hawaii International Conference on System Sciences, 1997, 2:94-103 vol.2.

[4] Litchfield, R.. 2009. "Brainstorming rules as assigned goals: Does brainstorming really improve idea quantity?" Spring Science and Business Media.

[5] Hernandez, N. V., Schmidt, L. C., Kremer, G. E. O., (2012). Experimental Assessment of TRIZ Effectiveness in Idea Generation.

[6] Geschka, Horst, Goetz R. Schaude, and Helmut Schlicksupp. 1976. "MODERN TECHNIQUES FOR SOLVING PROBLEMS.” International Studies of Management \& Organization 6 (4): 45-63.

[7] Dean, D. L., Hender, J. M., Rodgers, T. L., and Santanen, E. L., 2006. Identifying quality, novel, and creative ideas: Constructs and scales for idea evaluation. J. of the Association for Information Systems, 7(10): 646-699.

[8] Jin Y, Chusilp P (2006) Study of mental iteration in different design situations. Des Stud 27:25-55

[9] Lemons G, Carberry A, Swan C, Jarvin L, Rogers C (2010) The benefits of model building in teaching engineering design. Des Stud 31:288-309

[10] Yilmaz, S., Rosenberg, M. N., Daly, S. R., Jablokow, K. W., Silk, E. M., \& Teerlink, W. (2015, June). Impact of problem contexts on the diversity of design solutions: An exploratory case study.

[11] Daly, S., Yilmaz, S., Christian, J., Seifert, C., and Gonzalez, R., 2012. Design heuristics in engineering concept generation. Journal of Engineering Education, 101(4): 601-629.

[12] Silk, E. M., Daly, S. R., Jablokow, K. W., Yilmaz, S., \& Rosenberg, M. (2014, June).The design problem framework: Using adaption-innovation theory to construct design problem statements.

[13] Kirton, M. Adaptors and innovators: A description and measure. Journal of Applied Psychology 61 (5), 622-629, doi:10.1037/0021-9010.61.5.622 (1976).

[14] Helm, Kevin (2015) Improving Creative Output: Tools, Metrics, and Interventions, Schreyer Honors College Thesis. 


\subsection{Appendix A: Metrics}

This appendix contains all of the metrics used in this research. Because of difficulty implementing a completeness metric, completeness is not included. All metrics listed below were used with sufficient inter-rater reliability.

Acceptability Metric:

\begin{tabular}{|l|l|} 
Acceptability \\
\hline Score & Level Description \\
\hline 4 & $\begin{array}{l}\text { Common strategies that do not violate norms or } \\
\text { sensibilities }\end{array}$ \\
\hline 3 & $\begin{array}{l}\text { Somewhat uncommon or unusual strategies that do } \\
\text { not offend sensibilities }\end{array}$ \\
\hline 2 & $\begin{array}{l}\text { Offends sensibilities or totally unaccepted by } \\
\text { society }\end{array}$ \\
\hline 1 & $\begin{array}{l}\text { Radically violates laws or sensibilities. Totally } \\
\text { unacceptable business practice or totally unethical. }\end{array}$ \\
\hline
\end{tabular}

Applicability Metric:

\begin{tabular}{|l|l|}
\hline Applicability \\
\hline Score & Level Description \\
\hline 4 & $\begin{array}{l}\text { Solves an identified problem that is directly related to } \\
\text { the stated } \\
\text { problem (do X to get Y, and Y is part of the stated } \\
\text { problem) }\end{array}$ \\
\hline 3 & $\begin{array}{l}\text { Solves an implied problem that is related to the stated } \\
\text { problem (do X to get an implied Y, which applies to } \\
\text { the stated problem) }\end{array}$ \\
\hline 2 & $\begin{array}{l}\text { May have some benefit within a special situation and } \\
\text { somehow relates to the stated problem (do X, which } \\
\text { somehow relates to the stated problem) }\end{array}$ \\
\hline 1 & $\begin{array}{l}\text { Intervention is not stated or does } \\
\text { not produce a useful outcome (no X) or (do X for } \\
\text { useless Y) }\end{array}$ \\
\hline
\end{tabular}


Clarity Metric:

\begin{tabular}{|c|c|}
\hline \multicolumn{2}{|c|}{ Clarity } \\
\hline Score & Level Description \\
\hline 3 & $\begin{array}{l}\text { Well-developed written description or visual } \\
\text { representation. The components are clear and } \\
\text { commonly understood }\end{array}$ \\
\hline 2 & $\begin{array}{l}\text { Understandable but some of the descriptions or } \\
\text { drawings might not be commonly understood. } \\
\text { Contains fragments or obviously missing } \\
\text { components to make the concept clear }\end{array}$ \\
\hline 1 & $\begin{array}{l}\text { Written description and drawing are } \\
\text { vague/ambiguous. Difficult to understand. }\end{array}$ \\
\hline
\end{tabular}

Effectiveness Metric:

\begin{tabular}{|l|l|}
\hline \multicolumn{2}{|l|}{ Effectiveness } \\
\hline 4 & Level Description \\
\hline 3 & $\begin{array}{l}\text { Reasonable and will solve the stated problem without regard } \\
\text { for workability (if you could do it, it would solve the main } \\
\text { problem) }\end{array}$ \\
\hline 2 & $\begin{array}{l}\text { Reasonable and will contribute to the solution of the problem } \\
\text { (It helps, but is only a partial solution) }\end{array}$ \\
\hline 1 & $\begin{array}{l}\text { Unreasonable or unlikely to solve the problem (it probably } \\
\text { will not work) }\end{array}$ \\
\hline $\begin{array}{l}\text { Solves an unrelated problem (it would not work, even if you } \\
\text { could do it) }\end{array}$ \\
\hline
\end{tabular}


Implementability Metric:

Implementability
\begin{tabular}{|l|l|}
\hline Score & Level Description \\
\hline 4 & Low cost. No change to accommodate product \\
\hline 3 & $\begin{array}{l}\text { Reasonable cost. Some change necessary for } \\
\text { product }\end{array}$ \\
\hline 2 & $\begin{array}{l}\text { Very expensive. Significant change necessary for } \\
\text { product }\end{array}$ \\
\hline 1 & $\begin{array}{l}\text { Financially unviable. Unachievable changes need to } \\
\text { be made. }\end{array}$ \\
\hline
\end{tabular}

Implicational Explicitness Metric:

Implicational Explicitness
\begin{tabular}{|l|l|}
\hline Score & Level Description \\
\hline 3 & $\begin{array}{l}\text { Implication is clearly state and makes sense }(\mathrm{X}=> \\
\mathrm{Y})\end{array}$ \\
\hline 2 & $\begin{array}{l}\text { Implication is not generally accepted or vaguely } \\
\text { stated. (X might }=>\mathrm{Y}, \mathrm{X}=>\text { Y (vague) }\end{array}$ \\
\hline 1 & $\begin{array}{l}\text { Implication is not stated, even though it might be } \\
\text { relevant ( } \mathrm{X} \text { w/o } \mathrm{Y})\end{array}$ \\
\hline
\end{tabular}

